\title{
Body Mass Index, Body Weight Perception, and Depressed Mood in Korean Adolescents
}

\author{
Yooli Lim and Bongseog Kim \\ Department of Psychiatry, Sanggye Paik Hospital, Inje University, Seoul, Korea
}

Objectives: We examined the relationships between the body mass index, body weight perception, and depressed mood in a nationally representative sample of Korean adolescents.

Methods: We analyzed the data from the 2013 Korean Youth Risk Behavior Web-based Survey and evaluated the relationships between the body mass index, body weight perception, and depressed mood by gender ( 36655 boys and 35780 girls).

Results: For boys, a low body mass index and perceiving oneself as underweight were related to depressed mood. For girls, both low and high body mass indices were negatively related to depressed mood. In addition, self-perceptions of being underweight or overweight were positively related to depressed mood. Body weight perception was not a significant mediator in the relationship between body mass index and depressed mood.

Conclusion: These results suggest that both body mass index and body weight perception significantly contribute to Korean adolescents' depressed mood. Thus, research and clinical attention needs to be given to underweight as well as overweight adolescents, because those who perceive their weight as not normal are at risk for depression.

Key Words: Adolescence; Body mass index; Body weight perception; Depressed mood.

Received: June 6, 2016 / Revision: July 11, 2016 / Accepted: July 25, 2016

Address for correspondence: Bongseog Kim, Department of Psychiatry, Sanggye Paik Hospital, Inje University, 1342 Dongil-ro, Nowon-gu, Seoul 01757, Korea

Tel: +82-2-950-1088, Fax: +82-2-936-8069, E-mail: kimbs328@paik.ac.kr

\section{INTRODUCTION}

Mood instability and depression commonly occur in adolescence due to developmental changes, including physical and personal identity development. ${ }^{1)}$ Reportedly, 3-7\% of adolescents in America and 5-8\% of Korean adolescents experience depressed mood. ${ }^{2,3)}$ Several predictors of depressed mood in adolescence have been identified: grade in school, friendships, socioeconomic status, family problems, family history of depression, drinking alcohol, smoking, health problems, suicidal history, and body image dissatisfaction., ${ }^{4,5)}$

During adolescence, the perception of one's body, or body image, changes due to the rapid development and maturation of the body. This change affects identity formation and mood, and such dissatisfaction with body image can generate a depressed mood. ${ }^{6}$ Recently, obesity has emerged as a social issue that significantly impacts adolescents' perceived body image. The formation of an egosyntonic body image is important because dissatisfaction with body image during adolescence can generate anxiety, low self-esteem, peer isola-

This is an Open Access article distributed under the terms of the Creative Commons Attribution Non-Commercial License (http://creativecommons.org/licenses/by-nc/3.0) which permits unrestricted non-commercial use, distribution, and reproduction in any medium, provided the original work is properly cited. tion, and suicidal ideas, and it can continue to affect mental health into adulthood. ${ }^{7-9)}$ For this reason, there has been much research into the relationship between depressed mood, body mass index (BMI), and adolescent body weight perceptions.

Though some studies have shown a relationship between obesity and depressed mood, ${ }^{10)}$ body weight perception (BWP) has been found to have a greater effect on depressed mood than BMI. ${ }^{11,12)}$ However, the previous research identified no relationship between BWP and depressed mood in boys. ${ }^{13)}$ Most of the research has focused on girls, and there is scant research concerning gender differences in the relationships between BMI, body weight perception, and depressed mood. This study aimed to examine this issue among a sample of Korean adolescents. Additionally, we investigated body weight perception's mediating role in the relationship between BMI and depressed mood.

\section{METHODS}

\section{Participants}

This study was based on data from the 9th Korean Youth Risk Behavior Web-based Survey (KYRBWS 2013) conducted by the Ministry of Education, Ministry of Health and Welfare, 
and Korea Centers for Disease Control and Prevention. The survey has been conducted annually since 2005 to understand the status of health behaviors, evaluate and plan health promotions, and calculate health indicators. The survey targeted 400 middle schools and 400 high schools that agreed to participate in the online survey from June 1, 2013 to June 30, 2013 (with an additional testing period from July 1-18). Data obtained from 36655 boys and 35780 girls after obtaining written consent was analyzed by applying weighted values that represented 72435 adolescents in Korea. All personally identifiable information was removed before the data set was released for public use. This study was reviewed and approved by the Institutional Review Board of Sanggye Paik Hospital (SPIRB-2015-02-018).

\section{Instruments}

This study gathered self-reported data on the following variables: depressed mood, BMI $\left(\mathrm{kg} / \mathrm{m}^{2}\right)$, body weight perception, age, smoking experience, alcohol intake experience, suicidal ideation, unhealthy weight control behaviors, perceived economic status, academic performance, and city type. BMI was calculated using weight and height measurements obtained from physical examinations. It was categorized into three groups according to the World Health Organization's Asian Pacific guideline: underweight (BMI <18.5), normal weight (BMI 18.5-22), and overweight (BMI $\geq 23$ ).

To evaluate body weight perception, participants responded to the question, "What do you think about your body weight?" using the following response key: 1) very underweight, 2) slightly underweight, 3) normal, 4) slightly overweight, and 5) very overweight. The responses were classified into three groups: underweight (very underweight and slightly underweight), normal weight (normal), and overweight (slightly overweight and very overweight). Depressed mood was assessed by the participants' responding either "yes" or "no" to the question, "Have you ever felt sadness and despair bothersome enough to interfere with your daily living for at least two consecutive weeks over the past 12 months?"

Covariates included age, city type (metropolis, micropolis, countryside), perceived economic status (upper, middle, lower), academic performance (upper, middle, lower), smoking experience (yes or no), alcohol intake experience (yes or no), suicidal ideation (yes or no), and unhealthy weight control behaviors ( $0,1,2,3$ or more), as were used in previous studies. $^{14,15)}$ Suicidal ideation was evaluated through the question, "Have you ever seriously thought about suicide over the past 12 months?" Smoking experience was defined as smoking one or more cigarettes within the last 30 days, and alcohol intake was defined as drinking more than one glass of alcohol within the last 30 days. Unhealthy weight control

Table 1. Demographic characteristics of the participants with depressed mood

\begin{tabular}{|c|c|c|c|c|c|c|}
\hline & \multicolumn{6}{|c|}{ Depressed mood } \\
\hline & \multicolumn{3}{|c|}{ Boys $(n=9193)$} & \multicolumn{3}{|c|}{ Girls ( $n=13237)$} \\
\hline & Weighted (\%) & $p$-value & $\mathrm{n}$ & Weighted (\%) & p-value & $n$ \\
\hline \multicolumn{7}{|c|}{ Perceived economic status } \\
\hline Upper & 31.6 & & 2909 & 25.5 & & 3372 \\
\hline Middle & 41.2 & $<0.001$ & 3789 & 47.6 & $<0.001$ & 6298 \\
\hline Lower & 27.2 & & 2498 & 26.9 & & 3567 \\
\hline \multicolumn{7}{|c|}{ Academic performance } \\
\hline Upper & 30.5 & & 2807 & 28.9 & & 3833 \\
\hline Middle & 25.8 & $<0.001$ & 2370 & 26.7 & $<0.001$ & 3522 \\
\hline Lower & 43.7 & & 4016 & 44.4 & & 5882 \\
\hline \multicolumn{7}{|l|}{ City type } \\
\hline Metropolis & 46.4 & & 4267 & 45.0 & & 5952 \\
\hline Micropolis & 40.5 & 0.042 & 3721 & 43.2 & 0.055 & 5719 \\
\hline Countryside & 13.1 & & 1205 & 11.8 & & 1566 \\
\hline \multicolumn{7}{|l|}{ Suicidal ideation } \\
\hline Yes & 38.2 & $<0.001$ & 3529 & 43.2 & $<0.001$ & 5743 \\
\hline \multicolumn{7}{|c|}{ Alcohol intake experience } \\
\hline Yes & 59.1 & $<0.001$ & 5453 & 48.6 & $<0.001$ & 6603 \\
\hline \multicolumn{7}{|c|}{ Smoking experience } \\
\hline Yes & 40.6 & $<0.001$ & 3810 & 18.7 & $<0.001$ & 2562 \\
\hline
\end{tabular}


behavior was evaluated through the question: "Choose the ways you tried to control your weight over the past 30 days." Participants chose from 10 different ways that were then classified into 4 groups, based on the number of ways chosen: 0 , 1,2 , and 3 or more ways.

\section{Data analysis}

After dividing the sample into two groups according to gender, analysis was conducted to identify the characteristics associated with having experienced a depressed mood using a chi-square test and Student's t-tests (Table 1 and 2).

We also examined BWP as a mediator in the relationship between BMI and depressed mood (Fig. 1). As recommended by Baron and Kenny ${ }^{16)}$ and Holmbeck, ${ }^{17)}$ a mediation analysis was conducted. We tested 1) the relationship between BMI and BWP (Pathway A), 2) the relationship between BMI and depressed mood (Pathway C), 3) the relationship between BWP and depressed mood controlling for BMI (Pathway B), and 4) the relationship between BMI and depressed mood without controlling for BWP. Analysis was conducted using multivariate logistic regression, and odds ratios (ORs) were obtained. A probability level of $\mathrm{p}<0.05$ was used to indicate statistical significance. Pathway A was examined to calculate the OR of self-perceptions of being underweight or overweight in contrast to self-perceptions of normal weight for each BMI category. In Model 1, Pathway C examined the relationship between BMI and depressed mood without considering BWP. In Model 2, we tested the relationship between BMI and depressed mood, controlling for BWP. Pathway B examined the relationship between BWP and depressed mood, controlling for BMI. If BWP acts as a mediator, statistical significance will be reduced when BWP is included in the model (as in the case of Model 2) than when it is not included (as in Model 1). The data were analyzed using the Statistical Analysis System 9.0 (SAS 9.0; SAS Institute, Cary, NC, USA).

\section{RESULTS}

Table 1 and 2 report the percentage characteristics of participants according to depressed mood. $25.1 \%$ of boys $(n=9193)$ and $37.0 \%$ of girls $(n=13237)$ reported depressed mood.

Boys with normal BMI were more likely to report a depressed mood than were either underweight or overweight boys $(\mathrm{p}<0.001)$. BMI did not influence depressed mood in such a way for girls. Both boys and girls who perceived themselves as underweight or overweight were more likely to report a depressed mood than were adolescents who perceived

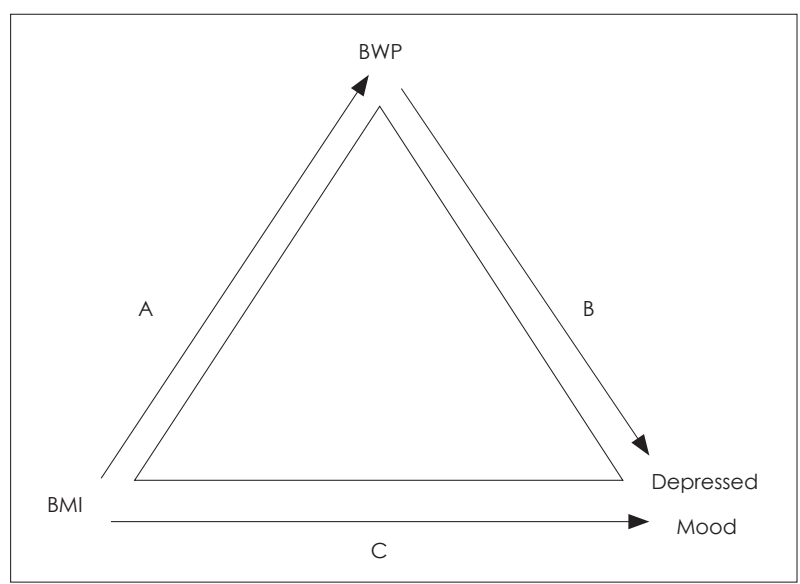

Fig. 1. Three conditions for the test of mediation of the relationship to body weight perception (BWP) in the relationship between body mass index (BMI) and depressed mood.

Table 2. Weight-related characteristics of participants with depressed mood

\begin{tabular}{|c|c|c|c|c|c|c|}
\hline & \multicolumn{6}{|c|}{ Depressed mood } \\
\hline & \multicolumn{3}{|c|}{ Boys $(n=9193)$} & \multicolumn{3}{|c|}{ Girls $(n=13237)$} \\
\hline & Weighted (\%) & p-value & $n$ & Weighted (\%) & p-value & $\mathrm{n}$ \\
\hline \multicolumn{7}{|l|}{ Body mass index } \\
\hline Underweight & 23.4 & & 2070 & 24.1 & & 3086 \\
\hline Normal weight & 51.7 & $<0.001$ & 4569 & 58.9 & 0.713 & 7536 \\
\hline Overweight & 24.9 & & 2196 & 17.0 & & 2172 \\
\hline \multicolumn{7}{|c|}{ Body weight perception } \\
\hline Underweight & 35.7 & & 3285 & 19.5 & & 2578 \\
\hline Normal weight & 30.2 & $<0.001$ & 2780 & 33.4 & $<0.001$ & 4429 \\
\hline Overweight & 34.1 & & 3128 & 47.1 & & 6230 \\
\hline \multicolumn{7}{|c|}{ Unhealthy weight control behaviors } \\
\hline 0 methods & 58.4 & & 5365 & 42.5 & & 5622 \\
\hline 1 method & 17.2 & $<0.001$ & 1580 & 14.7 & $<0.001$ & 1942 \\
\hline 2 methods & 16.0 & & 1476 & 25.4 & & 3368 \\
\hline 3 or more & 8.4 & & 772 & 17.4 & & 2305 \\
\hline
\end{tabular}


themselves as having a normal weight $(\mathrm{p}<0.001)$. Regardless of sex, depressed mood was more likely among those participants who reported more unhealthy weight control behaviors $(\mathrm{p}<0.001)$, lower perceived economic status $(\mathrm{p}<0.001)$, lower academic performance $(\mathrm{p}<0.001)$, and having experienced suicidal ideations $(\mathrm{p}<0.001)$, smoking $(\mathrm{p}<0.001)$, and alcohol intake $(\mathrm{p}<0.001)$. Boys who lived in a micropolis were less likely to report depressed mood than boys in either a metropolis or countryside environment $(\mathrm{p}=0.042)$. No significant differences were found among the girls in terms of city type $(\mathrm{p}=0.055)$.

We conducted multivariate logistic regression to identify the relationship between BMI and BWP, as represented by Pathway A in Fig. 1. Table 3 reports the relationship between BMI and BWP controlling for age, perceived economic status, academic performance, city type, alcohol intake experience, smoking experience, suicidal ideation, and unhealthy weight control behaviors. BMI was significantly associated with BWP, and both underweight and overweight adolescents of both sexes perceived their weight to be greater than did the normal weight individuals ( $\mathrm{p}<0.001$ ).

Table 4 presents the relationships between BMI and de- pressed mood both without (Model 1, Pathway C) and with (Model 2) BWP. We conducted multivariate logistic regression after adjusting for age, city type, perceived economic status, academic performance, smoking experience, alcohol intake experience, suicidal ideation, and unhealthy weight control behaviors. In Model 1 (BMI $\rightarrow$ Depressed Mood), underweight boys were significantly more likely to have experienced a depressed mood compared to normal weight boys $(\mathrm{p}<0.001)$, and both underweight and overweight girls were significantly less likely to have experienced a depressed mood compared to normal weight girls $(\mathrm{p}<0.001)$. There was no significant relationship between being overweight and having a depressed mood for the boys. In Model 2, after adjusting for BWP, underweight boys were significantly more likely to have had a depressed $\operatorname{mood}(\mathrm{p}<0.001)$, similar to Model 1; however, the OR was higher than that of Model 1. Both underweight and overweight girls were significantly less likely to have experienced a depressed $\operatorname{mood}(\mathrm{p}<0.001)$, similar to Model 1; however, the ORs for underweight and overweight girls were higher and lower, respectively, compared to Model 1. Boys who perceived themselves as underweight were significantly more likely to have experienced a

Table 3. Adjusted odds ratios and $95 \%$ confidence intervals for the association between body mass index and body weight perception

\begin{tabular}{|c|c|c|c|c|}
\hline & \multicolumn{4}{|c|}{ Body weight perception } \\
\hline & \multicolumn{2}{|c|}{ Boys } & \multicolumn{2}{|c|}{ Girls } \\
\hline & $\begin{array}{l}\text { Underweight compared } \\
\text { to approximately } \\
\text { normal weight }\end{array}$ & $\begin{array}{l}\text { Overweight compared } \\
\text { to approximately } \\
\text { normal weight }\end{array}$ & $\begin{array}{l}\text { Underweight compared } \\
\text { to approximately } \\
\text { normal weight }\end{array}$ & $\begin{array}{l}\text { Overweight compared } \\
\text { to approximately } \\
\text { normal weight }\end{array}$ \\
\hline \multicolumn{5}{|l|}{ Body mass index } \\
\hline Underweight & $0.092(0.086-0.100)^{*}$ & $4.251(3.603-5.015)^{*}$ & $0.079(0.073-0.085)^{*}$ & $6.590(5.863-7.408)^{*}$ \\
\hline Normal weight & 1.000 (Referent) & 1.000 (Referent) & 1.000 (Referent) & 1.000 (Referent) \\
\hline Overweight & $0.010(0.007-0.013)^{*}$ & $79.982(66.623-96.020)^{*}$ & $0.017(0.008-0.037)^{*}$ & $156.118(130.572-186.661)^{*}$ \\
\hline
\end{tabular}

Analyses using logistic regression test. ORs were adjusted for age, perceived economic status, academic performance, city type, alcohol intake experience, smoking experience, suicidal ideation, and unhealthy weight control behaviors. ${ }^{*} \mathrm{p}<0.001$

Table 4. Adjusted odds ratios and $95 \%$ confidence intervals regarding depressed mood by body mass index and body weight perception

\begin{tabular}{|c|c|c|c|c|}
\hline & \multicolumn{2}{|c|}{ Boys } & \multicolumn{2}{|c|}{ Girls } \\
\hline & Model $1^{\dagger}$ & Model $2^{\ddagger}$ & Model $1^{\dagger}$ & Model $2^{\ddagger}$ \\
\hline \multicolumn{5}{|l|}{ Body mass index } \\
\hline Underweight & $1.097(1.025-1.175)^{*}$ & $1.181(1.091-1.277)^{*}$ & $0.868(0.809-0.930) *$ & $0.883(0.811-0.960) *$ \\
\hline Normal weight & 1.000 (Referent) & 1.000 (Referent) & 1.000 (Referent) & 1.000 (Referent) \\
\hline Overweight & $0.927(0.855-1.005)$ & $1.033(0.922-1.156)$ & $0.761(0.698-0.829)^{*}$ & $0.753(0.678-0.837)^{*}$ \\
\hline \multicolumn{5}{|c|}{ Body weight perception } \\
\hline Underweight & & $1.149(1.065-1.239)^{*}$ & & $1.083(1.002-1.171)^{*}$ \\
\hline Normal weight & & 1.000 (Referent) & & 1.000 (Referent) \\
\hline Overweight & & $1.005(0.926-1.090)$ & & $1.069(1.009-1.133)^{*}$ \\
\hline
\end{tabular}

Analyses using logistic regression test. Model 1 odds ratios were adjusted for age, perceived economic status, academic performance, city type, alcohol intake experience, smoking experience, suicidal ideation, and unhealthy weight control behaviors. For Model 2, body weight perception was additionally adjusted. ${ }^{*} p<0.001$, ${ }^{\dagger}$ Model 1 excludes perceived weight, ${ }^{\ddagger}$ Model 2 includes perceived weight 
depressed mood $(\mathrm{p}<0.001)$, whereas there was no significant relationship with depressed mood for boys who perceived themselves to be overweight. Girls who perceived themselves as underweight or overweight were significantly more likely to have experienced a depressed $\operatorname{mood}(\mathrm{p}<0.001)$. There was no significant relationship found for BWP as a mediator in the relationship between BMI and depressed mood.

\section{DISCUSSION}

In this study, both underweight and overweight adolescents perceived themselves as being overweight when compared to normal weight adolescents. Based on previous research, girls favoring a thin body shape tended to misrecognize themselves as being fat even when they were underweight or normal. ${ }^{13,18)}$ Boys also perceived their body shapes as being fatter than their actual shapes. ${ }^{19)}$ Lee et al. ${ }^{20)}$ reported that $46.4 \%$ of female adolescents and $31.9 \%$ of male adolescents thought they were a bit or considerably fatter, and 3.2\% of them regarded themselves as being fat even when they were found to be underweight. Adolescents are likely to exhibit subjective distortion in their BWPs due to their physical growth and an increased concern over their appearance. In particular, social preferences for slim-bodied females and musclebound males, as influenced by mass media, may affect the weight perceptions of adolescents and result in body weight distortions.

Both underweight adolescent boys and those who perceived themselves as underweight showed a higher risk for depressed mood compared to normal weight boys. Other research reviewed that, unlike girls, boys who believed they were underweight expressed the greatest body dissatisfaction because of desiring a more muscular body. ${ }^{21)} \mathrm{A}$ study of male college students showed that risk of dissatisfaction with body shape, decline in self-regard, depression, and eating disorders increased when their actual amount of muscle was less than what they expected. ${ }^{22)}$ Unlike females, males express their toughness by using their bodies efficiently and by enacting survival instincts; therefore, boys with smaller bodies may become objects of ridicule and harassment by their peers, which can be directly associated to depression. ${ }^{23)}$

Adolescents with depression mainly express their mood with fatigue, somnolence, and various physical symptoms, which may be accompanied by sensitivity and impulsivity rather than demonstrations of somberness. ${ }^{24)}$ In this study, depressed mood was restrictively estimated by the assessment of experiences of sadness and despair with a duration of at least two weeks within the last 12 months. Adolescent girls who were underweight or overweight showed a lower risk for depressed mood compared to those who had a nor- mal BMI. One study reported that girls demonstrated a higher risk of depression when their BMI was either higher or lower than what was normal, ${ }^{25)}$ and this is contrary to the results of the present study. In addition, some studies reported that women overestimated and underestimated self-reported height and weight, respectively. ${ }^{26,27)}$ The classification of BMI into the three groups in this study may not have been as precise as we would have preferred because BMI was estimated by self-report questionnaire, a limitation that may cause the results to be inconsistent with previous studies on the relationship between BMI and depressed mood in female adolescents.

Girls who perceived themselves as underweight or overweight demonstrated a higher risk of depressed mood in this study. Similarly, in a study of female college students, those women who recognized themselves as being fat as well as those who recognized themselves as being thin showed higher dissatisfaction with their bodies, which was associated with depressive symptoms and lower self-regard. ${ }^{28)}$ Additionally, one longitudinal study showed that girls who perceive themselves as being overweight at the age of 14 have more mental health problems, including depression and anxiety, compared to those who perceived themselves as normal weight, and the risk of depression among adolescents was higher when body dissatisfaction was higher. ${ }^{11)}$ Given that females want to be thinner, a skinnier body in comparison to males, various psychological and sociocultural factors, and actual weight as a single variable, may affect the formation of a negative body image resulting in depression and anxiety.

Previous research has investigated the mediators in the relationships between BMI, BWP, and suicidal ideation in adolescents, ${ }^{15)}$ but no research has yet examined mediation in the relationships between BMI, BWP, and depressed mood. We attempted to identify a mediated effect in this study; however, BWP was not confirmed to be a significant mediator in the relationship between BMI and depressed mood. In this study, age, city type, perceived economic status, academic performance, smoking experience, alcohol intake experience, suicide ideation, and unhealthy weight control behaviors were controlled in conducting the analysis. However, adolescent depression is affected by various other risk factors: biological factors, such as family history and comorbidity; sociocultural factors, such as divorce, death, and child-rearing attitude of parents; and psychological factors, such as personal disposition and characteristics. ${ }^{29)}$ BWP may also be influenced by objective weight, mass media, peer relationships, and other sociocultural factors; ${ }^{9)}$ thus, objective weight and subjective recognition of body shape may affect depression independently and may be influenced 
by various other factors.

This study has several limitations. First, it used data from a large anonymous online survey that used self-report to assess BMI and subjective feelings of sadness; therefore, it was limited in its ability to objectively assess BMI and depressive symptoms. Future research should measure height and weight directly and use an objective method of assessing depressive symptoms in adolescents when evaluating the associations between depressed mood, BMI, and BWP. For example, the Korean version of the Children's Depression Inventory could be used. Second, this study was cross-sectional and therefore limited in being able to identify any causal relationships. Moreover, a causal relationship between depressed mood, BMI, and BWP cannot be asserted because depressed mood was assessed based on the past (i.e., sadness and despair for a duration of two weeks over the past 12 months), while BMI and BWP were assessed based on current physical states. Future studies with longitudinal designs are needed for the identification of causal relationships.

\section{CONCLUSION}

Despite these limitations, the results of this study, using a nationally representative sample of adolescent boys and girls, suggest that both underweight and overweight adolescents are likely to perceive themselves as being overweight, and that subjective BWP may be significantly associated with adolescent depression more so than objective weight. Because depression and BWP in adolescence can influence adulthood, it becomes even more important to develop accurate BWPs during adolescence by providing youth with environments that encourage a healthy body, rather than just skinny or muscular bodies for girls and boys, respectively. Therefore, educational approaches are needed to help adolescents maintain appropriate weight as a means to managing physical and mental health and correctly acknowledging their body weight. For instance, school-based interventions, including dietary guidelines, physical activity programs, and health care classes, should be established for adolescents. Parents and school health professionals should closely monitor not only BMI scores of adolescents but also their BWPs.

\section{Acknowledgments}

This work was supported by a National Research Foundation of Korea (NRF) Grant funded by the Korean Government (MSIP) (No. 2013R1A1A3008158).

\section{Conflicts of Interest}

The authors have no financial conflicts of interest.

\section{REFERENCES}

1) Cho SC, Kim JW. Psychiatric disorders in adolescence. J Korean Med Assoc 2008;51:176-186.

2) Ahn DH. Mental disorders in adolescents. J Korean Med Assoc 2009;52:745-757.

3) Costello EJ, Mustillo S, Erkanli A, Keeler G, Angold A. Prevalence and development of psychiatric disorders in childhood and adolescence. Arch Gen Psychiatry 2003;60:837-844.

4) Kim MY, Kang YJ. Depression and related factors for adolescents. J Korean Soc Sch Health 2000;13:261-270.

5) Park HS, Koo HY, Jang EH. The study on predictors of depression for Korean female adolescents. J Korean Acad Nurs 2007;37:715723.

6) Shin NY, Shin MS. Body dissatisfaction, self-esteem, and depression in obese Korean children. J Pediatr 2008;152:502-506.

7) Kim DS. Body image dissatisfaction as an important contributor to suicidal ideation in Korean adolescents: gender difference and mediation of parent and peer relationships. J Psychosom Res 2009; 66:297-303.

8) Ozmen D, Ozmen E, Ergin D, Cetinkaya AC, Sen N, Dundar PE, et al. The association of self-esteem, depression and body satisfaction with obesity among Turkish adolescents. BMC Public Health 2007;7:80.

9) Xie B, Liu C, Chou CP, Xia J, Spruijt-Metz D, Gong J, et al. Weight perception and psychological factors in Chinese adolescents. J Adolesc Health 2003;33:202-210.

10) Anderson SE, Cohen P, Naumova EN, Jacques PF, Must A. Adolescent obesity and risk for subsequent major depressive disorder and anxiety disorder: prospective evidence. Psychosom Med 2007;69: 740-747.

11) Al Mamun A, Cramb S, McDermott BM, O'Callaghan M, Najman JM, Williams GM. Adolescents' perceived weight associated with depression in young adulthood: a longitudinal study. Obesity (Silver Spring) 2007;15:3097-3105.

12) Smolak L. Body image in children and adolescents: where do we go from here? Body Image 2004;1:15-28.

13) Harring HA, Montgomery K, Hardin J. Perceptions of body weight, weight management strategies, and depressive symptoms among US college students. J Am Coll Health 2010;59:43-50.

14) Byeon $\mathrm{H}$. The relationship between BMI, weight perception and depression-like symptoms in Korean middle school students. J Korea Acad-Industr Coop Soc 2013;14: 6317-6323.

15) Kim DS, Cho Y, Cho SI, Lim IS. Body weight perception, unhealthy weight control behaviors, and suicidal ideation among Korean adolescents. J Sch Health 2009;79:585-592.

16) Baron RM, Kenny DA. The moderator-mediator variable distinction in social psychological research: conceptual, strategic, and statistical considerations. J Pers Soc Psychol 1986;51:1173-1182.

17) Holmbeck GN. Toward terminological, conceptual, and statistical clarity in the study of mediators and moderators: examples from the child-clinical and pediatric psychology literatures. J Consult Clin Psychol 1997;65:599-610.

18) Kim JY, Son SJ, Lee JE, Kim JH, Jung IK. The effects of body image satisfaction on obesity stress, weight control attitudes, and eating disorders among female junior high school students. J Korean Home Econ Assoc 2009;47:49-59.

19) Jung IK. A study on body image perception and weight control by degree of obesity in male students. Korean Education Inquiry 2006; 24:31-39.

20) Lee Y, Shin HK, Choi BM, Eun BL, Park SH, Lee KH et al. A survey of body shape perception and weight control of adolescent girls in three areas of Korea. Korean J Pediatr 2008;51:134-144.

21) Cohane GH, Pope HG Jr. Body image in boys: a review of the literature. Int J Eat Disord 2001;29:373-379.

22) Olivardia R, Pope HG Jr, John J, Borowiecki III JJ, Cohane GH. 
Biceps and body image: the relationship between muscularity and self-esteem, depression, and eating disorder symptoms. Psychol Men Masc 2004;5:112-120.

23) McCabe MP, Ricciardelli LA. Body image dissatisfaction among males across the lifespan: a review of past literature. J Psychosom Res 2004;56:675-685.

24) Stringaris A. Irritability in children and adolescents: a challenge for DSM-5. Eur Child Adolesc Psychiatry 2011;20:61-66.

25) Cortese S, Falissard B, Angriman M, Pigaiani Y, Banzato C, Bogoni G, et al. The relationship between body size and depression symptoms in adolescents. J Pediatr 2009;154:86-90.

26) Engstrom JL, Paterson SA, Doherty A, Trabulsi M, Speer KL. Ac- curacy of self-reported height and weight in women: an integrative review of the literature. J Midwifery Womens Health 2003;48:338345.

27) Sherry B, Jefferds ME, Grummer-Strawn LM. Accuracy of adolescent self-report of height and weight in assessing overweight status: a literature review. Arch Pediatr Adolesc Med 2007;161:1154-1161.

28) Lox CL, Osborn MC, Pellett TL. Body image and affective experiences of subjectively underweight females: implications for exercise behavior. J Appl Biobehav Res 1998;3:110-118.

29) Ryoo KY, Shin YK, Eun BL, Park SH, Tocko YC. Adolescent depression in a provincial city. J Korean Pediatr Soc 2000;43:172-178. 